\title{
A High-Performance Stand-Alone Solar PV Power System for LED Lighting
}

\author{
José António Barros Vieira ${ }^{1}$ and Alexandre Manuel Mota ${ }^{2}$ \\ ${ }^{1}$ Escola Superior de Tecnologia de Castelo Branco, Unidade Técnico Cientifica de Engenharia Electrotécnica e Industrial, \\ Avenida Empresário, 6000 Castelo Branco, Portugal \\ ${ }^{2}$ Departamento de Electrónica Telecomunicações e Informática, Universidade de Aveiro, 3810 Aveiro, Portugal
}

Correspondence should be addressed to José António Barros Vieira; zevieira@ipcb.pt

Received 19 April 2013; Accepted 11 June 2013

Academic Editors: O. Badran and M. Beccali

Copyright (C) 2013 J. A. B. Vieira and A. M. Mota. This is an open access article distributed under the Creative Commons Attribution License, which permits unrestricted use, distribution, and reproduction in any medium, provided the original work is properly cited.

\begin{abstract}
This paper presents new improvements and real result of a stand-alone photovoltaic power system for LED lighting that was developed previously. The actual system, during day, charges a lead acid battery using MPPT algorithm for power transfer optimization, and, during night, it supervises battery discharge and controls the current in the power LED array. The improvements are in hardware and software. The hardware was simplified using only one DC/DC converter and only one microcontroller making it more efficient. The system board uses an ATMEL ATTINY861V microcontroller, a single-ended primary inductance converter (SEPIC), and sensors to read input and output voltages and currents to control all system. The software improvements are made in the battery charging algorithm, battery discharging algorithm, and in current control of the power LED array adjusting the light intensity. Moreover, results are presented showing the balance of energy in a period of 24 hours: first results of the MPPT algorithm in bulk battery charge phase and then the over battery charge phase, both in a sunny day. The power LED current control results are also presented showing a very small error. It turns off at $00: 00$ at each day to reduce the waste of energy. Finally, the balance of energy is studied and presented to help the right projection of the PV power panel needed and the necessary battery capacity.
\end{abstract}

\section{Introduction}

The use of stand-alone photovoltaic lighting system has increased in remote rural areas and in towns. Conventional street lighting is energy intensive and can represent a high cost to local governments, which creates an impetus to investigate more efficient light sources such as photovoltaic(PV-) powered light emitting diodes (PLEDs) lighting systems. Photovoltaic system is gaining increased importance as a renewable source due to its advantages such as little maintenance and no noise and wear due to its absence of moving parts. But there are still two principal barriers to the generalization use of photovoltaic systems: the high installation cost and the low energy conversion efficiency. To increase the ratio output power/cost of installation it is important that PV panel operates in its maximum power point (MPP) to absorb the maximum power possible. The combination of PV panels with power LEDs makes the called new green light sources.
Battery is the energy store element in this system. State measure and energy management are critical issues for the battery in PV LED lighting system, such as the state of charge (SOC) [1].

(1) The fast charging capability may not be obtained because of the weather uncertainty.

(2) The charge time is limited by the sunshine time every day.

(3) Under charging usually happens to shorten the battery life since the PV panel size is limited by economy consideration.

The battery charge and discharge processes should be made correctly to enlarge its durability maximizing the stored energy $[2,3]$. To reduce the PV panel size it is important to maximise the power transference from PV panel to battery using some maximum power point tracker (MPPT) like the Perturbation and Observation (P\&O) algorithm [4-6]. P\&O 
algorithm is a very popular algorithm duo to its simplicity, convergent capacities, and to its low computational needs.

To create light with good yield the LED is the best option, it has been widely used and investigated having many advantages: high luminous efficiency, low environment pollution, long life, and firmness. LED lighting system supplied by batteries is one of most popular solutions to home, public lighting, vehicle, and signalizing lighting system [5-12].

Autonomous LED lighting system consists in three major parts: batteries, lighting controller module, and LED array module. Boost DC/DC converter is usually used as main circuit of the lighting controller module $[5,9]$. It is not easy to control the brightness of LED lighting system, due to its nonlinearity electrical characteristics, and temperature sensitivity [5, 9]. In [9], it is refereed that constant voltage control has disadvantages relatively to constant current control. However, conventional simple constant current control strategy may cause overcurrent and overheats if the control algorithm ignores LED temperature characteristics [9].

This work proposes an intelligent, economic, and efficient system to control a stand alone photovoltaic lighting system. It presents improvements in charging algorithm, in particular in $\mathrm{P} \& \mathrm{O}$ algorithm, improvements in monitoring the battery discharge, and in LED array current control algorithm. These improvements will considerably improve the stand alone photovoltaic lighting results.

During day, the battery is charged using the photovoltaic panel energy and, during night, the power LED brightness is controlled with the PI algorithm always supervising the battery discharge energy consumption. This is the first work that makes such a system using only one DC/DC converter, in this case, a Single Ended Primary Inductance Converter (SEPIC), reducing hardware costs. As the input voltage of the SEPIC can be higher or lower than the output voltage, this converter presents obvious design advantages [4].

The input and output modules connected to the SEPIC correctly changed using two switches controlled by the microcontroller.

This paper is divided into six sections, as follows. Section 1 is the introduction. Section 2 presents the system architecture. Section 3 presents the charging controller and energy management strategy. Section 4 presents high power LED module and brightness control strategy. Section 5 shows solar PV power LED lighting system characteristics. Section 6 shows experimental results. ending with conclusions presented in Section 7.

\section{System Architecture}

The proposed PV lighting system generates energy from sunlight by PV panel during the day, and illumination load only works at night, and a battery is adopted for energy storage. The most common battery type used is the valve regulated lead-acid (VRLA), because of its low cost, maintenance-free operation, and high efficiency characteristics $[4,13]$. The system also needs a long life and environmental illumination source, and high power white LED fits well this demand.
Figure 1 shows the block diagram of the proposed lighting system which is composed of a PV panel, a unique DC/DC converter regulated by the electronic and microcontroller module, a VRLA battery, and a high power white LED array. The PV lighting system controller is used to achieve battery charge regulation, to execute MPPT algorithm, and to control brightness intensity. The DC/DC converter is used to interface the PV panel to the battery using the two switches (switch 1 and switch 2). The same DC/DC converter is also used to provide the power to the high power white LED array from the battery. An NTC sensor is used to measure the battery temperature that is needed to battery charge algorithm.

In PV lighting system, choosing the electronic components is very important for cost reduction, reliability, and efficiency $[2,7]$. PV panel and high power white LED array are the most expensive components of the overall system, so the microcontroller board should make full use of them.

\section{Charging Controller and Energy Management Strategy}

A detailed block diagram of the charge regulation module is shown in Figure 2 (similar to Figure 1 but with switches 1 and 2 connected as showed in Figure 2). The system consists of a nonlinear current source, an SEPIC, a battery, and electronics and the microcontroller board. The SEPIC is used to interface PV to battery controlling its charge.

In this system, in order to save components and to increase system efficiency, the power converter acts not only as a maximum power point tracker but also as a charger to manage the state-of-charge of the battery by regulating the charging current or voltage. In this case, control of the power converter is actually a multiobjective control problem. Rather than being controlled to serve as a sole voltage or current regulator, the power converter is required to regulate and balance the power flow between the solar array and the battery under different insolation and load conditions.

3.1. Charging Control Strategy. The complete battery charging demands to the controller a complex control strategy, in which it would be possible to charge the battery, between its limits, in the faster possible way since working periods of energy generation of the PV panel are limited [14]. To achieve a fast, safe, and complete battery lead-acid charging process, some of the manufacturers recommend dividing the charging process in four stages $[2,3]$ that are designated by: $\left(1^{\circ}\right)$ trickle charge, $\left(2^{\circ}\right)$ bulk charge, $\left(3^{\circ}\right)$ over charge and $\left(4^{\circ}\right)$ float charge illustrated in Figure 3.

3.1.1. $1^{\circ}$ Stage (from $T_{0}$ to $T_{1}$ ) -Trickle Charge. This first stage appears when the battery voltage is below the value $V_{\text {CHGENB }}$ This voltage value, specified for the manufacturers, shows that the battery arrives at its critical discharge capacity. In this condition the battery should receive a small charge current defined by $I_{\mathrm{TC}}$ that has a typical value of $C / 100$ where $C$ is the normal battery capacity with a 10 hours charging process. This small current $I_{\mathrm{TC}}$ is applied until the battery voltage 


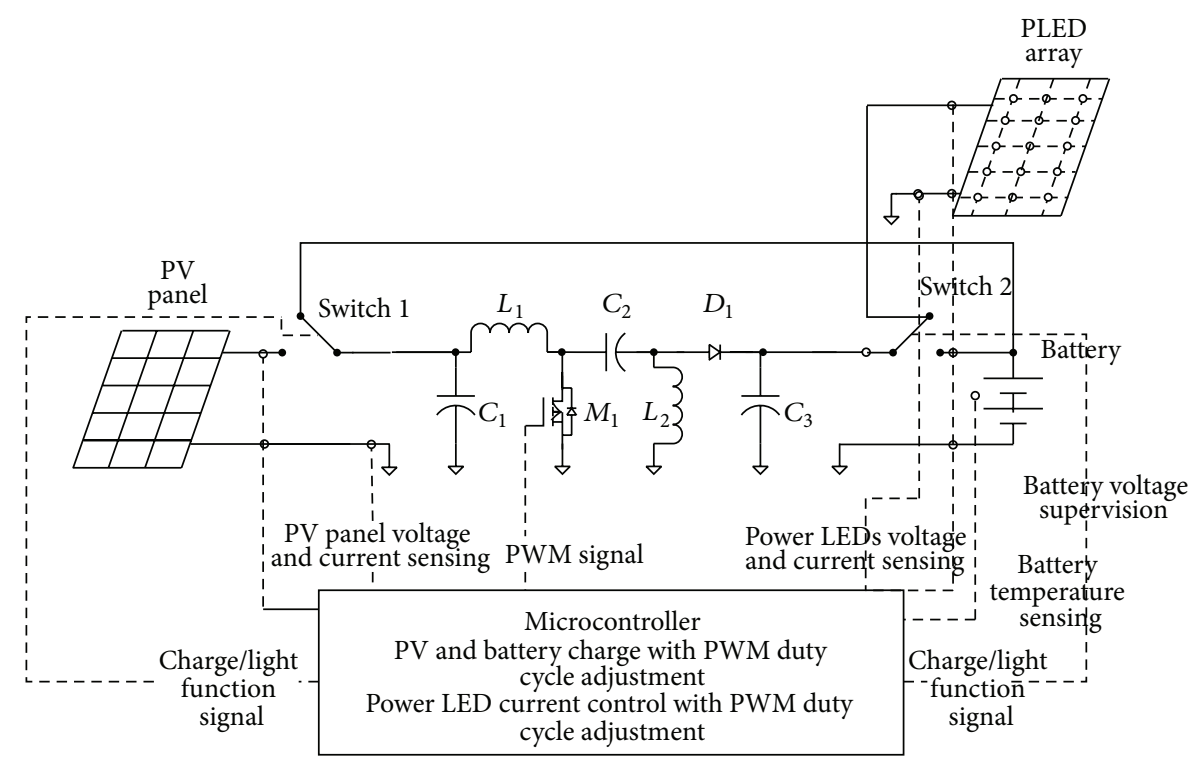

FIGURE 1: Stand alone photovoltaic lighting block diagram (PWM used to define the duty cycle).

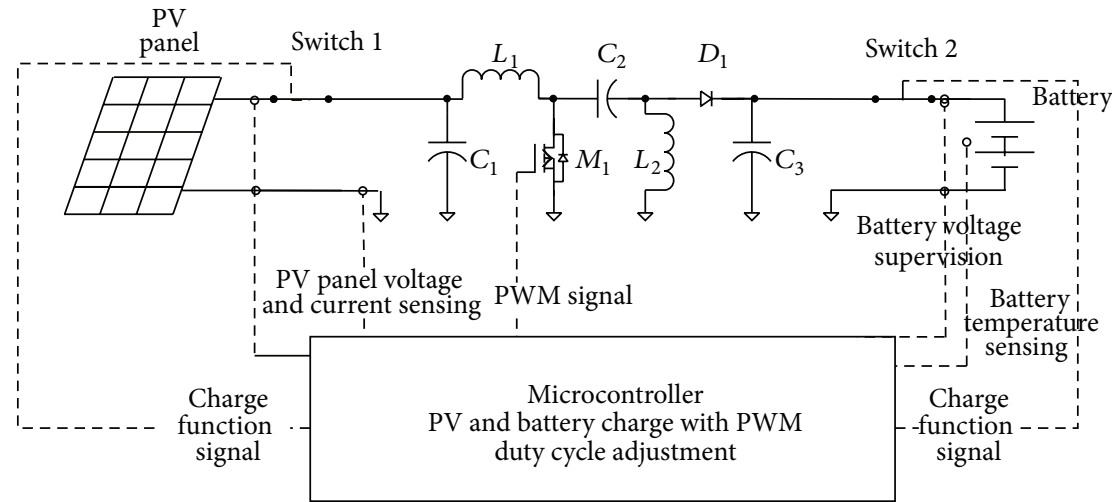

Figure 2: Photovoltaic battery charging block diagram (PWM used to define the duty cycle).

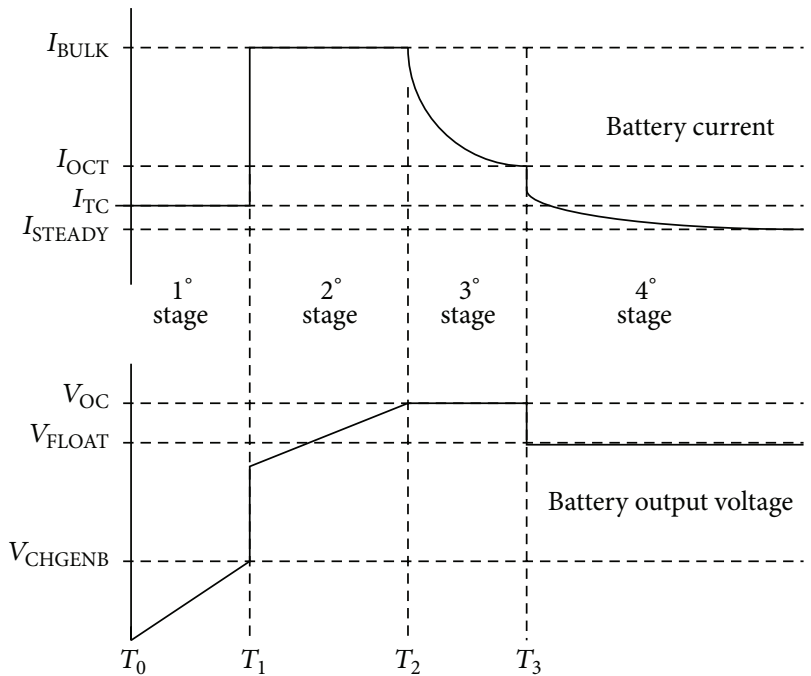

FIGURE 3: Current and voltage curves in the four stages of battery charging. reaches the value of $V_{\mathrm{CHGENB}}$. This stage also avoids that some accident could happen in the case when the one battery element is in curt circuit; therefore if this really happens the battery voltage will not grow and then the battery charging process does not pass for the next stage.

3.1.2. $2^{\circ}$ Stage (from $T_{1}$ to $T_{2}$ ) -Bulk Charge. After the battery voltage reaches the value $V_{\text {CHGENB }}$ it delivers to the battery a constant current $I_{\mathrm{BULK}}$. The $I_{\mathrm{BULK}}$ is the maximum charge current that battery supports without a big water losing, and its value is specified by the manufacturers. This current is applied until the battery voltage reaches the maximum value of overcharge voltage, defined by $V_{\text {OC }}$ and specified by the manufacturers.

3.1.3. $3^{\circ}$ Stage (from $T_{2}$ to $T_{3}$ )-Overcharge. During this stage the control algorithm should regulate the battery voltage in the $V_{\mathrm{OC}}$ so that the complete charge has been reached. When the charging current falls down to a preestablished value $I_{\text {OTC }}$ 


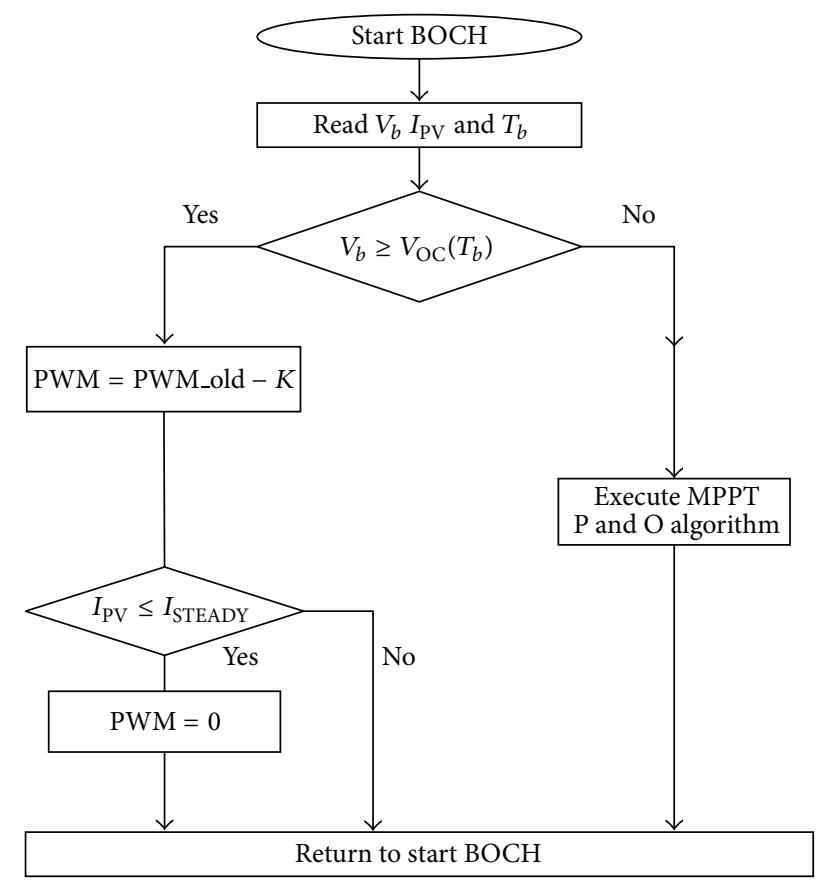

Figure 4: Battery charging algorithm with two main stages (bulk and overcharge (BOCH) stages) (PWM used to define the duty cycle).

and the voltage stays in the value $V_{\mathrm{OC}}$, the next stage will be executed. The value of $I_{\mathrm{OCT}}$ is around $10 \%$ of the $I_{\mathrm{BULK}}$.

3.1.4. $4^{\circ}$ Stage (from $T_{3}$ until the End)-Float Charge. In this stage the control algorithm will apply in the battery a constant voltage $V_{\mathrm{FLOAT}}$ which is a specified value by the battery manufacturers. This voltage is applied to the battery with the objective to avoid its auto-discharge. During the discharging process the battery voltage will fall down and when it achieves $0.9 V_{\text {FLOAT }}$ the control algorithm will execute again the $2^{\circ}$ stage providing the $I_{\mathrm{BULK}}$ current. The control algorithm only returns to the $2^{\circ}$ stage if the PV panel is producing energy, if not the battery will continue the discharge process that could reach a voltage below the value $V_{\mathrm{CHGENB}}$; in this situation the control algorithm should restart the charging process in $1^{\circ}$ stage when the PV panel will have energy again.

In this work there are some simplifications made in the implementation of the four different charging stages of a leadacid battery. The $1^{\circ}$ stage was not implemented because the discharge battery with this prototype board does not pass below $V_{\text {FLOAT }}$ (minimum lowest security voltage specified by the battery manufacturers). In this situation the applied load is disconnected from the battery by the control algorithm to avoid reaching critical discharge. The value of $V_{\text {FLOAT }}$ depends onor is a function of the battery temperature. The $4^{\circ}$ stage was not implemented but the $3^{\circ}$ stage is continued until the charge current reaches $I_{\mathrm{STEADY}}\left(10 \%\right.$ of $\left.I_{\mathrm{BULK}}\right)$ and finally the charging process is ended. When the PV panel has energy to deliver and the battery voltage is below the $V_{\mathrm{OC}}$ the control algorithm executes the $2^{\circ}$ stage. The battery charging algorithm implemented in this work can be seen in Figure 4 .

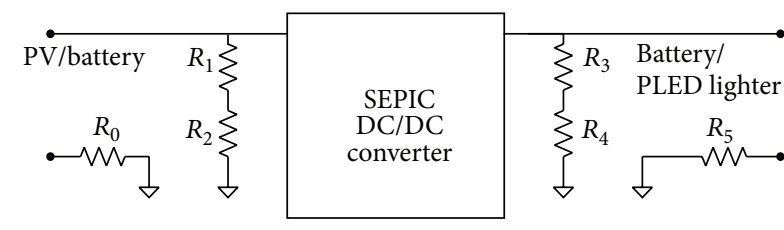

FIGURE 5: Voltage and current sensors for battery charging algorithm and voltage and current sensor for LED lighting current control.

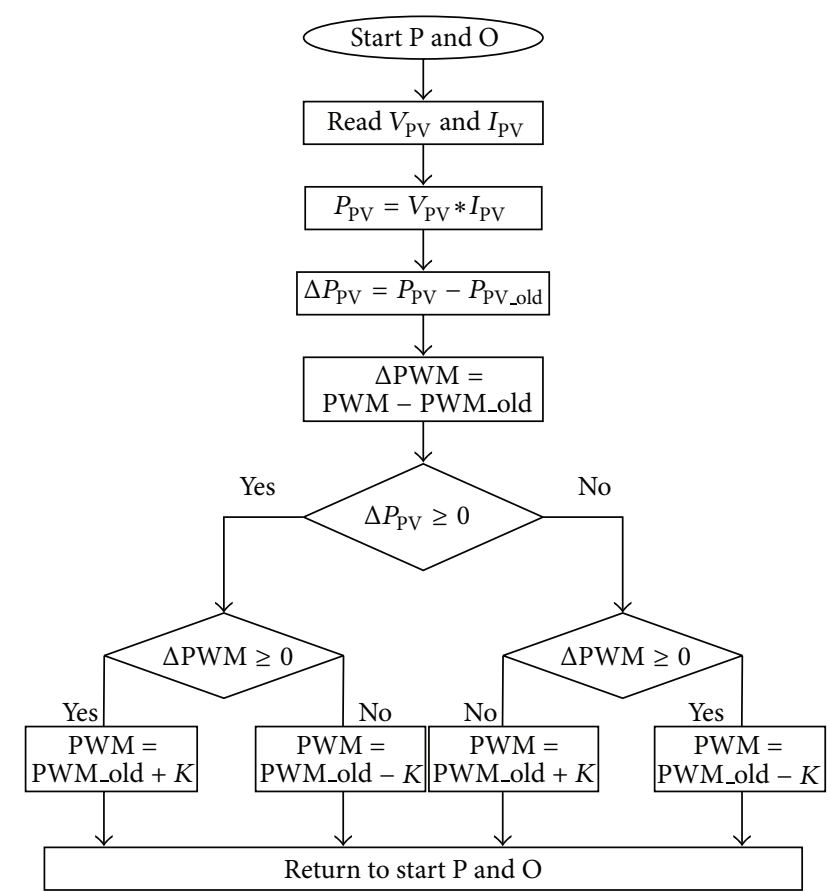

FIGURE 6: P\&O MPPT algorithm (PWM used to define the duty cycle applied in the MOSFET gate).

The parameter $K$ is the step given to the duty cycle of the PWM signal. $V_{b}$ and $I_{\mathrm{PV}}$ are the battery voltage and delivered current from PV panel and $T_{b}$ is the battery temperature. The maximum value of the $V_{\mathrm{OC}}$ depends on the battery temperature $V_{\mathrm{OC}}\left(T_{b}\right)$. From Figure 4 it is clear that only the $2^{\circ}$ and the $3^{\circ}$ stages are implemented from the four stages proposed in $[2,3]$.

In the $2^{\circ}$ stage of the battery charge, the use of an MPPT algorithm is very important to maximize the absorbed PV panel energy reducing the PV power needed. The correct choice of the PV panel power should guarantee that the $I_{\mathrm{BULK}}$ is never overcome.

3.2. MPPT Algorithm. The $\mathrm{P} \& \mathrm{O}$ is one of the so called "hillclimbing" MPPT methods, which is based on the VoltagePower $(V-P)$ of the PV characteristic curve [15], on the left side of the hill of the $V-P$ curve, the variation of the power is positive when $\mathrm{d} P / \mathrm{d} V>0$, at the right side is negative $\mathrm{d} P / \mathrm{d} V<0$. If the operating voltage of the PV panel is perturbed in a given direction and $\mathrm{d} P / \mathrm{d} V>0$, it is known that the perturbation moved the panel's operating point toward 


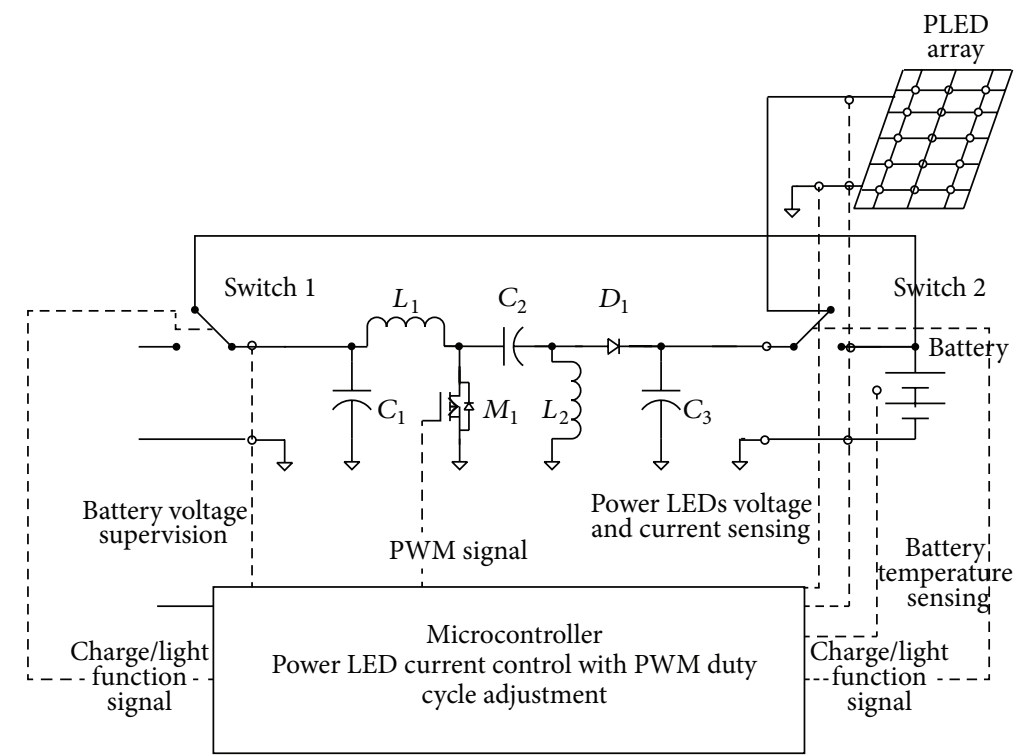

FIGURE 7: Power LED lighting block diagram (PWM used to define the duty cycle).

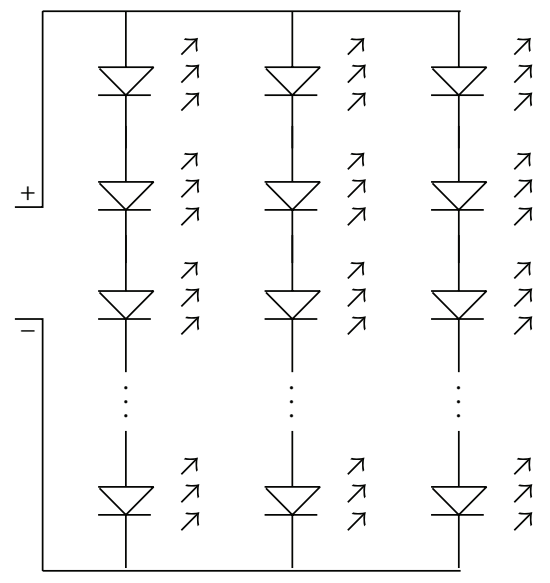

FIGURE 8: PLED array.

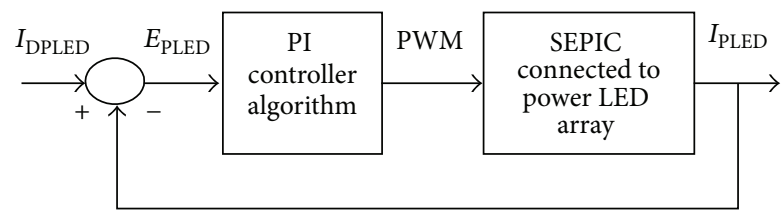

FIGURE 9: Block diagram of the PLED current controller (PWM used to define the duty cycle).

the MPP. The $\mathrm{P} \& \mathrm{O}$ algorithm would then continue to perturb the PV panel voltage in the same direction. If $\mathrm{d} P / \mathrm{d} V<0$, then the perturbation in operating point moved the PV panel away from the MPP, and the $\mathrm{P} \& \mathrm{O}$ algorithm reverses the direction of the perturbation [16]. The main advantage of the $\mathrm{P} \& \mathrm{O}$ method is that it is easy to implement, and it has low computational demand. However, it has some limitations, like oscillations around the MPP in steady state operation, slow response speed, and tracking in wrong way under rapidly

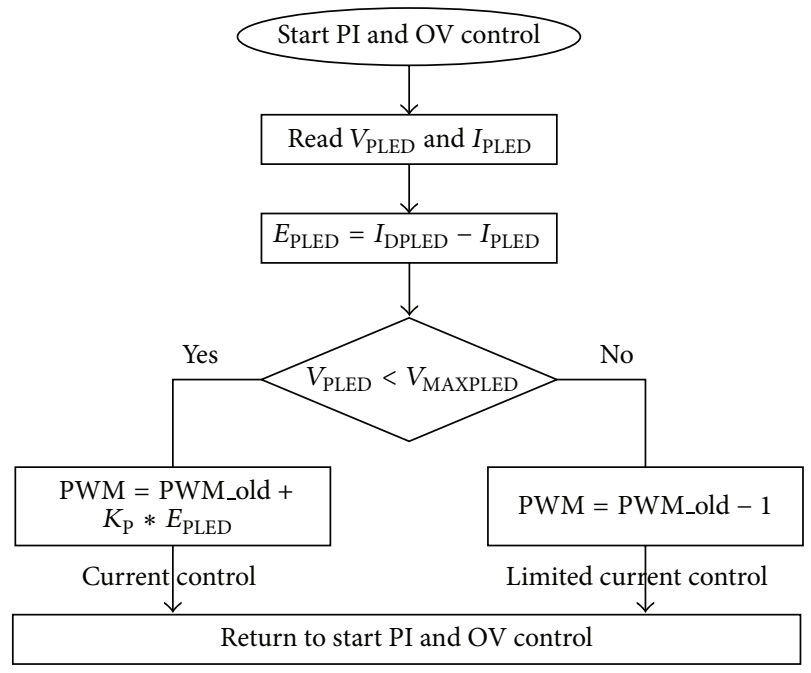

FIgURE 10: PLEDs PI current control and overvoltage supervision algorithm (PWM used to define the duty cycle).

changing in sun radiations or the appearing of shadows $[2$, $16,17]$. To reduce the presented limitations it will be useful to use a small sampling period. The used sampling period is 200 milliseconds.

Using the SEPIC with current and voltage resistor sensors illustrated in Figure 5, the P\&O MPPT algorithm was implemented with some improvements. The MPPT algorithm needs only the PV voltage and current information, and the battery voltage information is needed to control the battery charging and monitor its discharge.

$R_{0}=R_{5}$ and respective $V_{R 0}$ are $V_{R 5}$ are the voltages used to measure input and output SEPIC currents $I_{\mathrm{PV}}$ and $I_{\mathrm{LED}} \cdot R_{1}=R_{3}, R_{2}=R_{4}$, and its voltages are used to measure input and output SEPIC voltages $V_{\mathrm{PV}}$ and $V_{\mathrm{BAT}}$. 


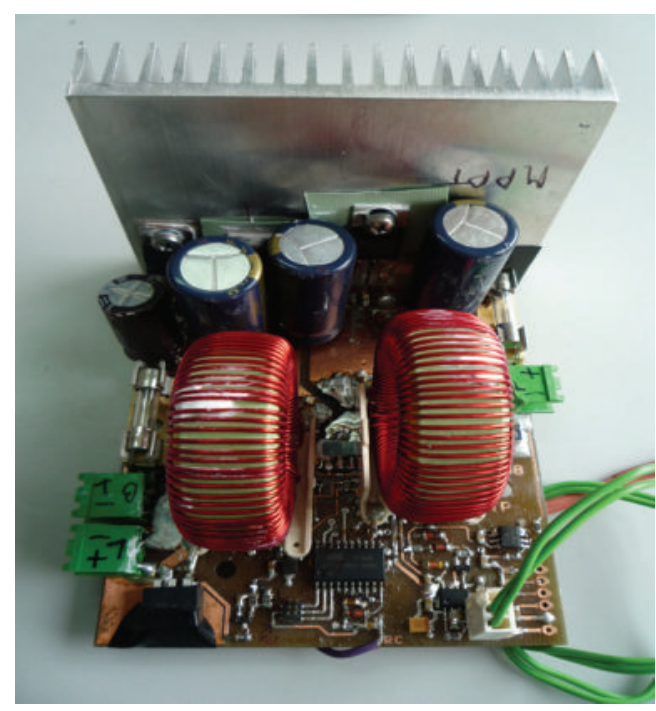

FIGURE 11: Photo of the prototype electronic board.

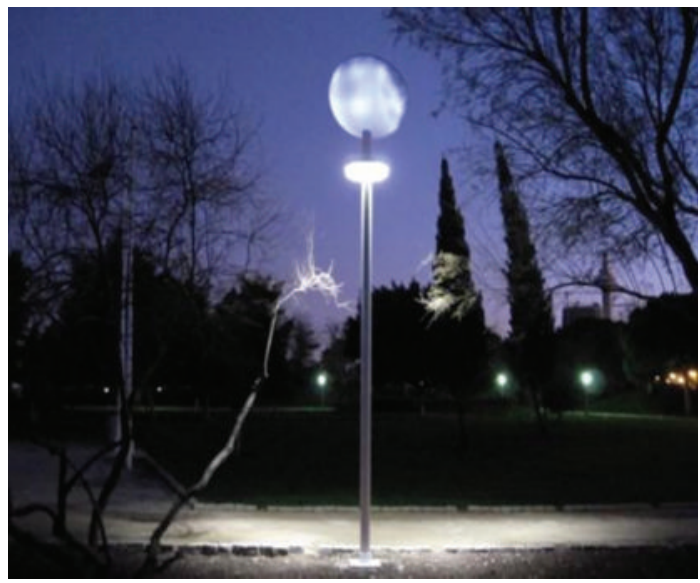

FIgURE 12: Photo of the stand alone photovoltaic lighting prototype.

The microcontroller uses 6 analogue-to-digital (A/D) converters with 10 bits and with one fast mode PWM signal to control the lighting system. The period of the PWM signal is $100 \mathrm{KHz}$.

The flow chart of the implemented P\&O MPPT algorithm is illustrated in Figure 6.

The parameter $K$ is the step given to the duty cycle of the PWM signal. This parameter is a function of the working point of the DC/DC converter, linear or nonlinear region. The $K$ parameter is inverse proportional to the current absorbed from the PV panel to get fast convergence to the MPP tracker. It is expected that this algorithm shows some inherent oscillation around the MPP [7].

3.3. Discharge Monitoring. In the developed prototype the algorithm also supervises the battery discharge because, for correct working periods of the lead-acid battery its voltage cannot go below a certain value established by the manufacture. If the discharge goes deep several times the good working battery periods will be smaller than the ones achieved without these deep discharges.

The microcontroller supervises the battery voltage and when the battery voltage goes below a certain value, which means that its level of discharge is big, the battery is disconnected from the power LED load by the microcontroller with switch 2. To make these switches (switch 1 and switch 2) there are two P channel MOSFETs driven with electronics and controlled by the microcontroller.

Next day, after a new charge period, the battery could be connected again to the power LED lighting array.

The advantages of the proposed improvements are (a) better exploitation of the power produced by the PV power source (b) increased battery lifetime by restoring the maximum possible energy in battery in the shortest time possible.

\section{High Power LED Module and Brightness Control}

The PV lighting system uses high power white LEDs and the same SEPIC used in charging algorithm. This SEPIC is projected to fit specific requirements such as high efficiency, long service-lift, and reduced size. The circuit components can provide a steadyand high efficiency (typically greater than $85 \%$ ) operation state for the $19 \mathrm{~W}$ high power LED array used in the PV lighting system. A detailed block diagram of the current LED controller is showed in Figure 7. The SEPIC is designed according to the system power requirements. It can supply a maximum output current of 4.0 Ampere to drive the LED array. With overvoltage protection and output current control feedback it is able to maintain a constant LED brightness.

4.1. Power LED Lighting System. The power LEDs used to make the lighting system are white with 3.2 and $400 \mathrm{~mA}$ each to give the maximum brightness at low working temperature. The number of PLEDs used to make the PLED lighting system is chosen to achieve a desired brightness.

There are 15 PLEDs, 3 frames in parallel of 7 PLEDs each, connected in series, as illustrated in Figure 8. The PLED lighting system will consume about $19 \mathrm{~W}$ of power working at maximum brightness that the PLED can give.

The system has a real-time clock (RTC) to control the illumination time; it turns on when night comes and turns off around 12 p.m. or another programed hour every day if battery has enough power.

To reduce the PLED lighting brightness variations with temperature changes, the PLEDs need an efficient dissipation material behind them to avoid the overheating of the LEDs providing a low temperature working point. The prototype of the LED lighting systems has 15 power LED with a large dissipation metal area. The PLEDs are from OSRAM.

A lens is used to focus the PLED brightness to the floor making a desired illumination area in the floor.

4.2. PI Current Control Algorithm. The brightness of the proposed lighting system is defined measuring and controlling the current in the PLED array. When the lighting system 


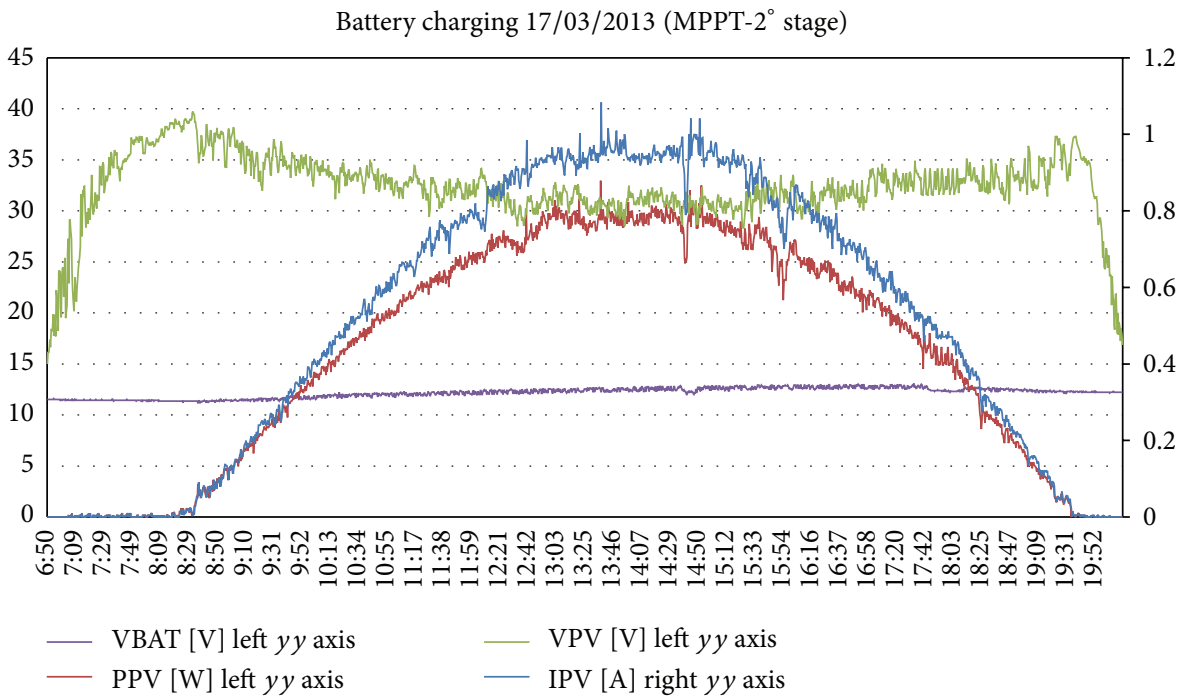

FIGURE 13: Part of the bulk charging phase of the battery charging process results.

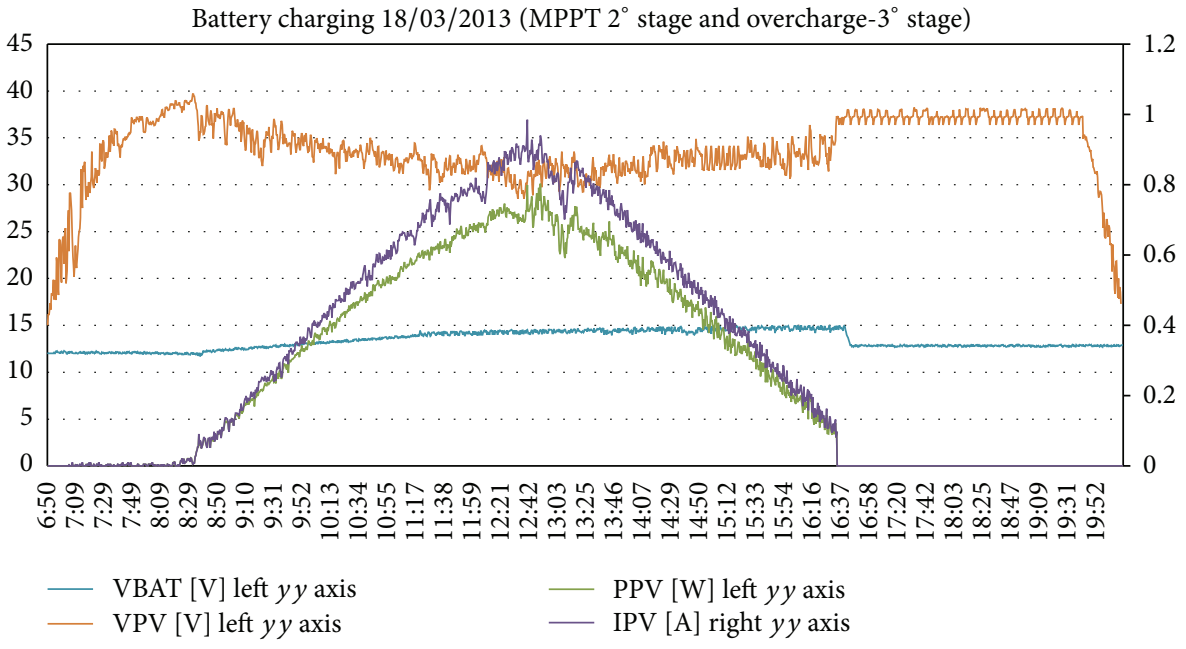

FIGURE 14: Part of the overcharging phase of the battery charging process results.

is turned on the current control algorithm uses a soft start because the DC/DC does not work correctly with big current transitions. After the soft start, the Proportional Integral (PI) controller starts working adjusting the PWM signal to take the current $\left(I_{\mathrm{PLED}}\right)$ to the desired current $\left(I_{\mathrm{DPLED}}\right)$ forcing a zero error $\left(E_{\mathrm{PLED}}\right)$ as illustrated in block diagram of Figure 9.

The proposed current control is a simplify proportional on and Integral controller based

$$
\text { PWM }=\text { PWM_old }+K_{P} * E_{\text {PLED }} \text {, }
$$

where the PWM is the control signal applied in the SEPIC MOSFET, PWM_old is the previous control signal applied, $E_{\text {PLED }}$ is the error between the desired and real currents and $K_{P}$ is a gain. A sampling period of 200 milliseconds is used.

The proposed lighting system turns on when night comes or it is too dark and turns off at a programmed hour (p.e. 00:00). The proposed lighting system will be used in public park illumination and after that hour there is no need to be turned on.

The current controller algorithm also supervises the output PLEDs voltage array to detect an open LED frame or an overvoltage hardware error situation.

The algorithm measures the PLED array voltage $\left(V_{\mathrm{PLED}}\right)$, and knowing the maximum security voltage $\left(V_{\text {MAXPLED }}\right)$, if the PLED array voltage is smaller than the maximum PLED array voltage, it runs the simplified PI control algorithm and if it is bigger, it limits the applied current as can be seen in Figure 10.

The lighting PLED system algorithm achieved good current control results even with battery voltage variation caused by the different battery levels of charge. 


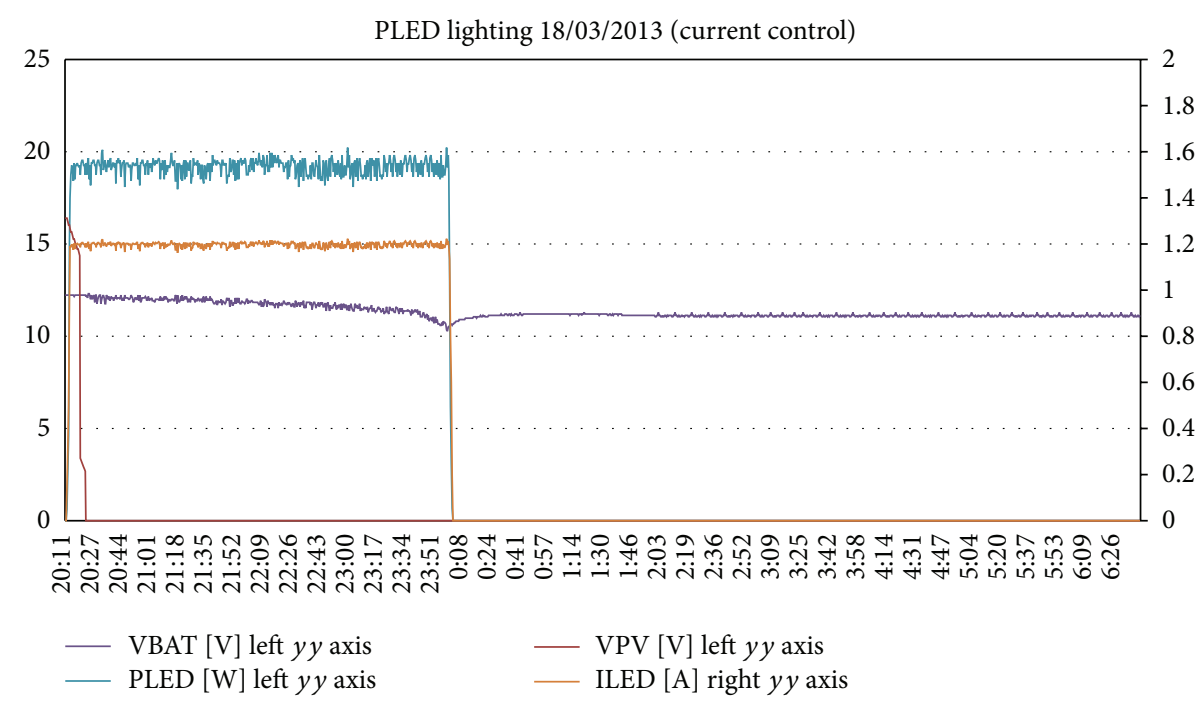

FIGURE 15: Current control results during night.

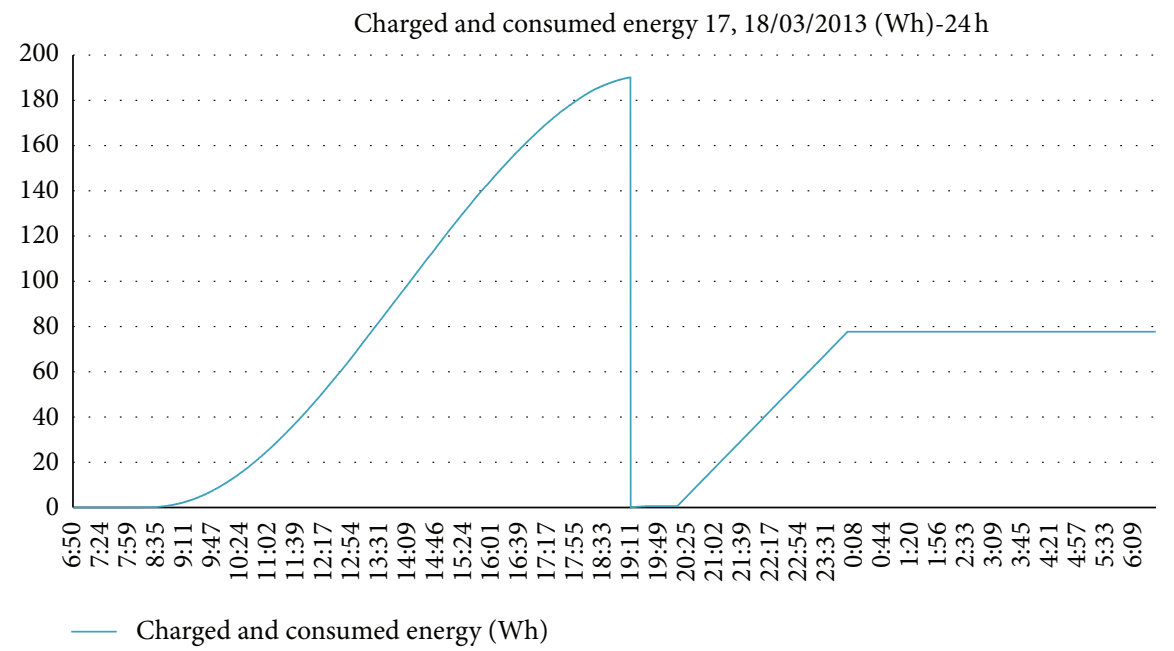

FIGURE 16: Charged and consumed accumulated energy during 24 hours (from the 190 Wh given by the PV panel during day $85 \%$ are accumulated $(161 \mathrm{Wh}))$ and $78 \mathrm{Wh}$ of consumed energy during night.

\section{Solar PV Power LED Lighting System Characteristics}

The practical experimental PV lighting system consists of a $30 \mathrm{~W}$ PV panel, $12 \mathrm{~V} 20$ Ah VRLA CSB battery, a $19 \mathrm{~W}$ high white PLED array, and the microcontroller board with the necessary electronics.

It is used a 30 Watt PV panel with a $V_{\mathrm{PP}}=30$ Volt and $I_{\mathrm{PP}}=1$ Ampere

The VRLA battery has $12 \mathrm{~V} / 20 \mathrm{Ah}$. The maximum charge current $I_{\text {BULK }}$ should be $10 \%$ of $20 \mathrm{Ah}$, with a maximum current that comes from the PV panel of 2.0 Ampere the latest condition is always verified. It is also important that battery has enough capacity to maintain the system working even in periods without charge (shadow or rainy days).

The power LED characteristics are $3.2 \mathrm{~V}$ and $400 \mathrm{~mA}$ for the maximum brightness. To have a lighting system with the desired brightness there are 15 PLEDs, 3 frames in parallel of 5 PLEDs each connected in series consuming about $19 \mathrm{~W}$ (16.0 $\mathrm{V}$ and 1.2 Amp).

The microcontroller is an ATTINY861V of the ATMEGA family that runs the two main algorithms: charge and supervise discharge algorithm and PLED current control algorithm. The microcontroller always supervises the PV voltage and current; if $V_{\mathrm{PV}}$ is bigger than $14.0 \mathrm{~V}$ and $I_{\mathrm{PV}}$ is near zero Ampere, the proposed lighting system starts the charge and monitor discharge algorithm, described in Section 3. When $I_{\mathrm{PV}}$ is near zero Ampere and $V_{\mathrm{PV}}$ is below $14.0 \mathrm{~V}$ the proposed system starts the PLED current control algorithm.

The implemented prototype electronic board with SEPIC, microcontroller, and the necessary electronics components is illustrated in Figure 11.

In the right side of the board, the PV panel input connection $(M)$ can be seen and in the left side the connection to 
the battery output/input connection $(B)$ and the load output connection $(L)$ that connects to the power LED lighting system. In the right side down there is the NTC temperature connection sensor to monitor the battery temperature.

Figure 12 shows the prototype of the stand alone photovoltaic lighting system installed in a public park in Lisbon, Portugal.

\section{Experimental Results}

In Figure 13, part the bulk charging phase of the batterycharging process for a $30 \mathrm{~W}$ nominal power PV source is shown. During this phase, the maximum available PV power is transferred to the battery stack, according to the MPPT algorithm.

In Figure 14, part of the overcharge phase is initiated when the battery voltage rises to $14.6 \mathrm{~V}$ and the battery charging current is progressively reduced to $0.1 \mathrm{Amp}$ at the end of this phase. At the end of the this phase, the battery is left in open-circuit condition and the battery voltage measured after $20 \mathrm{~h}$ was found to be $12.9 \mathrm{~V}$, corresponding to $100 \%$ battery state of charge, thus proving the success of the charging algorithm.

Figure 15 shows the current control process where the system continuously works all night, the current is controlled to remain stable at a value of 1.2 Ampere to give a constant brightness. The error range was controlled in \pm 0.08 Ampere to meet the actual demand. The LED lighting system is disconnected at 00:00 by the microcontroller.

Figure 16 shows the charged and consumed energy for the example day (a sunny day 18/03/2013). As can be seen the accumulated energy is approximated twice of the consumed energy. This fact is important to have the battery almost allways charged and in shadow days at night the lighting system also works using the stored energy.

\section{Conclusions}

This work presents an improved PV lighting system with MPPT, battery charger, high power White LEDs, and selfadapting brightness control. The microcontroller based on ATMEGA (ATTINY861V) is used to implement the system control in different operating states, including MPPT, charging, and lighting. In charging circuit, improvements in Perturbs \& Observed MPPT method for PV array and improvements in charging strategy for VRLA battery are implemented; in lighting circuit, $19 \mathrm{~W}$ high power white LED array and it is lighting power module can work in a highefficiency state; self-adapting current control for maintaining a constant brightness is implemented. Experimental results also verify the performance of the proposed photovoltaic lighting system and its energy balance. The proposed stand alone public lighting system presented several improvements like the use of only one DC/DC converter and a real-time clock that can be used to save energy or reduce the brightness after a predefined hour.

\section{References}

[1] Y. Liqiang, C. Zhiping, H. Xianlai, G. Junjie, and Z. Zhengming, "Design and implementation of photovoltaic lighting system with high luminous efficacy LEDs," in Proceedings of the IEEE 7th International Power Electronics and Motion Control Conference-ECCE Asia, pp. 2914-2918, Harbin, China, June 2012.

[2] K. Hesse, "An off-line lead-acid charger based on the UC3909," Tech. Rep., Unitrod Company, 1997.

[3] R. H. Rosemback, Conversor CC-CC Bidirecional Buck-Boost atuando como Controlador de Carga de Baterias em um Sistema Fotovoltaico [M.S. thesis], University Federal de Juiz de Fora, 2004.

[4] J. A. Barros Vieira and A. M. Mota, "Maximum power point tracker applied in batteries charging with PV panels," in Proceedings of the IEEE International Symposium on Industrial Electronics (ISIE '08), pp. 202-207, Oxford, UK, July 2008.

[5] Y. Heng, Design of Led Lighting Converter and Examples, Electrical Press, Beijing, China, 2008.

[6] Y. K. Cheng and K. W. E. Cheng, "General Study for using LED to replace traditional lighting devices," in Proceedings of the 2nd International Conference on Power Electronics Systems and Applications (ICPESA '06), pp. 173-177, Hong Kong, November 2006.

[7] Y. Ai, T. Liu, and S. Wang, "Design and implementation of a novel high-performance stand-alone photovoltaic LED lighting system," in Proceedings of the Asia-Pacific Power and Energy Engineering Conference (APPEEC '10), March 2010.

[8] M. O. Holcomb, R. Mueller-Mach, G. O. Mueller et al., "The LED Lightbulb: are we there yet? progress and challenges for solid state illumination," in Proceedings of the IEEE Conference on Lasers and Electro-Optics (CLEO '03), pp. 240-243, Baltimore, Md, USA, June 2003.

[9] B. Sheng, The design of serial/parallel white led driver IC with current-regulated based on boost converter [M.S. thesis], Jilin University, Chang Chun, China, 2007.

[10] J. Zhang, S. Pei-shi, and L. Haitao, "Design of photovoltaic charger of led street lamp for intelligent zed community," Chinese Journal of Power Sources, vol. 31, no. 2, pp. 157-159, 2007.

[11] J. A. B. Vieira and A. M. Mota, "Implementation of a stand-alone photovoltaic lighting system with MPPT battery charging and LED current control," in Proceedings of the IEEE International Conference on Control Applications (CCA '10), pp. 185-190, Yokloama, Japan, September 2010.

[12] D. Gacio, J. M. Alonso, A. J. Calleja, J. Garcia, and M. RicoSecades, "A universal-input single-stage high-power-factor power supply for HB-LEDs based on Integrated Buck-Flyback Converter," in Proceedings of the 24th Annual IEEE Applied Power Electronics Conference and Exposition (APEC '09), pp. 570-576, February 2009.

[13] C. Hua and J. Lin, "An on-line MPPT algorithm for rapidly changing illuminations of solar arrays," Renewable Energy, vol. 28, no. 7, pp. 1129-1142, 2003.

[14] N. Femia, G. Petrone, G. Spagnuolo, and M. Vitelli, “Optimizing sampling rate of $\mathrm{P} \& \mathrm{O}$ MPPT technique," in Proceedings of the IEEE 35th Annual Power Electronics Specialists Conference (PESC '04), pp. 1945-1949, June 2004.

[15] D. P. Hohm and M. E. Ropp, "Comparative study of maximum power point tracking algorithms using an experimental, programmable, maximum power point tracking test bed," in 
Proceedings of the IEEE 28th Photovoltaic Specialists Conference, pp. 1699-1702, September 2000.

[16] A. Brambilla, M. Gambarara, A. Garutti, and F. Ronchi, "New approach to photovoltaic arrays maximum power point tracking," in Proceedings of the 30th Annual IEEE Power Electronics Specialists Conference (PESC '99), pp. 632-637, July 1999.

[17] M. A. E. Galdino and C. M. Ribeiro, "An intelligent battery charge controller for small scale PV panel," in Proceedings of the 12th European Photovoltaic Solar Energy Conference and Exhibition, 1994. 


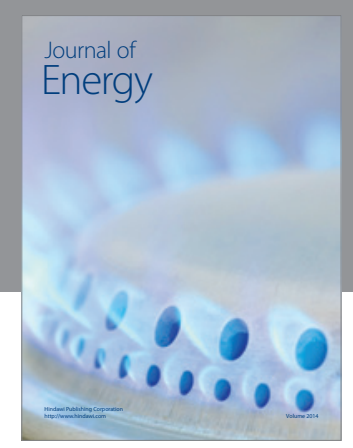

Journal of

Industrial Engineering
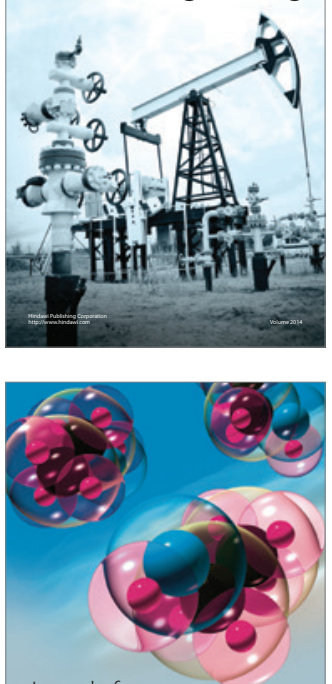

Fuels
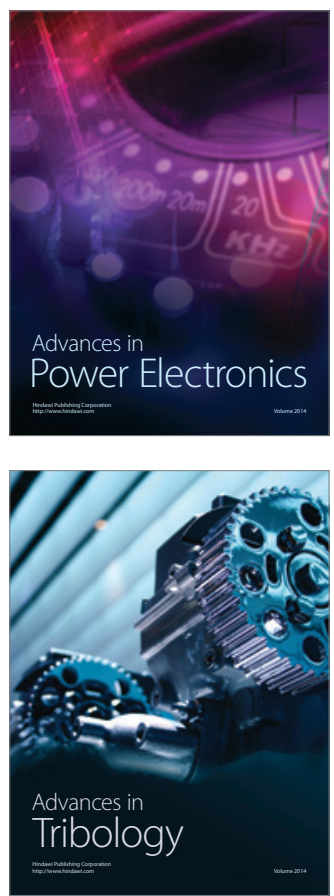

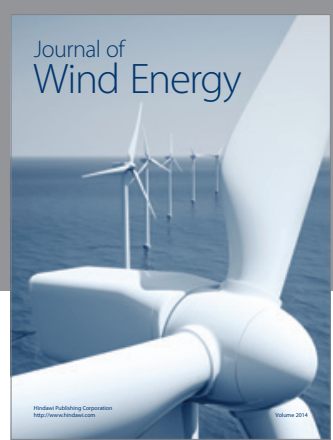

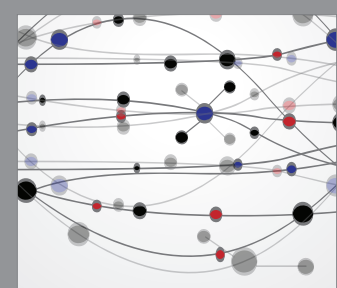

The Scientific World Journal

Submit your manuscripts at http://www.hindawi.com

Journal of

Structures
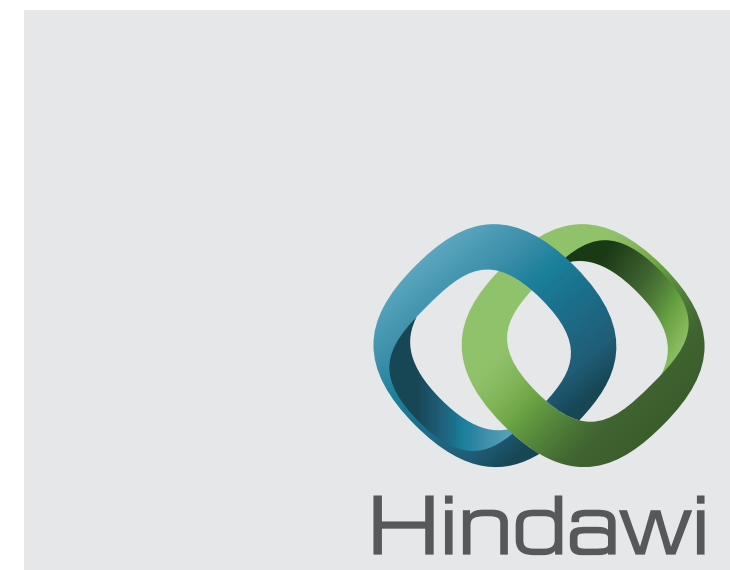

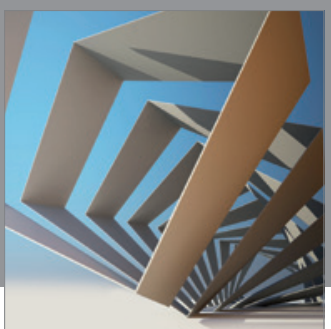

Rotating

Machinery
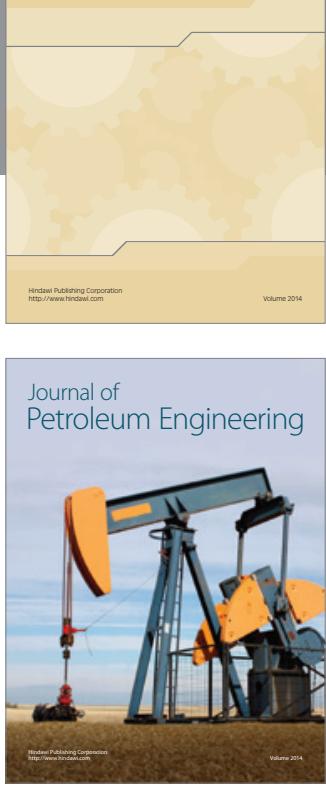

Journal of

Solar Energy
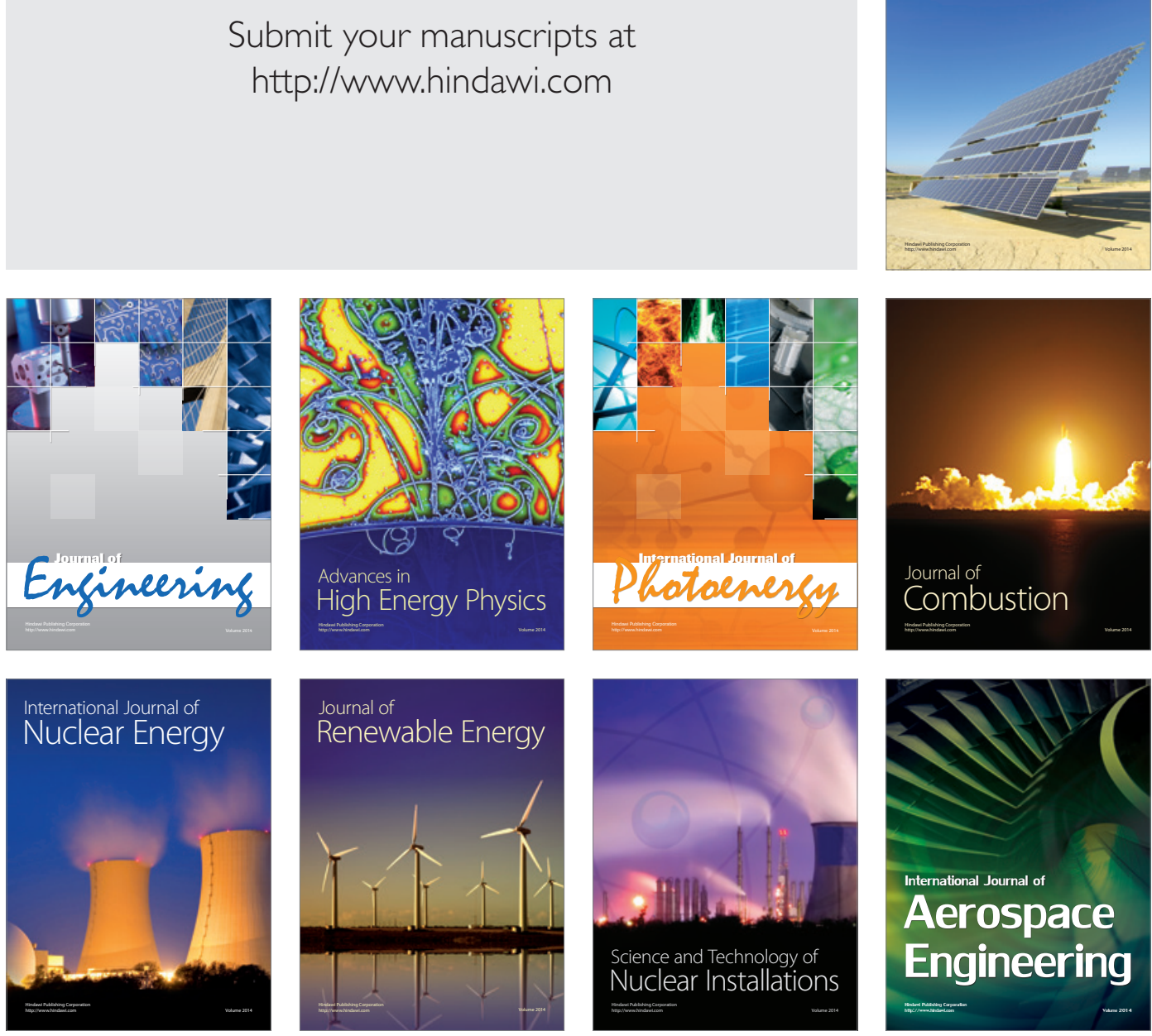